\title{
Grau de desenvolvimento regional dos municípios da mesorregião oeste catarinense: caracterização e classificação
}

\author{
Regional development degree of the municipalities of Santa Catarina west \\ meso region: characterization and classification
}

\section{Degré de développement régional des municipalités de la région ouest de Santa Catarina: caractérisation et classification}

\author{
Grado de desarrollo regional de los municipios de la región oeste de Santa Catarina: \\ caracterización y clasificación
}

\author{
Sérgio Begnini* \\ Lirane Elize Defante Ferreto de Almeida**
}

Recebido em 30/03/2016; revisado e aprovado em 08/09/2016; aceito em 18/10/2016

DOI: http:/ / dx.doi.org/10.20435/1984-042X-2016-v.17-n.4(01)

\begin{abstract}
Resumo: O objetivo deste estudo é classificar os municípios das cinco microrregiões que formam a mesorregião oeste catarinense segundo o grau de desenvolvimento regional, utilizando a análise fatorial. Por meio da análise fatorial, possibilitou-se extrair as cargas fatoriais para a construção do índice e do grau de desenvolvimento. As microrregiões assemelham-se, tanto nos aspectos culturais, produtivos, econômicos e de colonização, quanto na classificação, segundo o grau de desenvolvimento regional calculado. Conclui-se que ainda há muito que fazer para alcançar um desenvolvimento regional equitativo, considerando os municípios de cada microrregião da mesorregião.
\end{abstract}

Palavras-chave: desenvolvimento regional; análise fatorial; microrregião.

Abstract: The objective of this study is to classify the municipalities of five microregions that make up the Santa Catarina western region according to the regional development degree, using the factor analysis. By means of the factor analysis, it was possible to extract the factorials loads for the index construction and the development degree. The microregions resemble, both in cultural, productive, economic aspects and of colonization, as in rank, according to the degree of regional development calculated. It is concluded that there is still much to do to achieve equitable regional development, considering the municipalities of each micro-region of the middle region.

Key words: regional development; factor analysis; microregions.

Résumé: L'objectif de cette étude est de classer les municipalités de cinq microrégions qui composent la région de l'ouest de Santa Catarina, selon le degré de développement régional, à l'aide de l'analyse factorielle. Par le biais de l'analyse factorielle fait permis d'extraire les factorielles des charges pour la construction de l'indice et le degré de développement. Les microrégions ressemblent, tant dans les aspects culturels, productives et économiques et de la colonisation, comme dans rang, selon le degré de développement régional calculé. Il est conclu qu'il y a encore beaucoup à faire pour parvenir à un développement régional équitable, considérant les municipalités de chaque microrégion de la mesorigion.

Mots-clés: développement régional; analyse factorielle; microrégion.

Resumen: El objetivo de este estudio es clasificar los municipios de cinco micro regiones que conforman la región oeste de Santa Catarina, según el grado de desarrollo regional, mediante el análisis factorial. Mediante el análisis factorial hecho permitido extraer los factoriales cargas para la construcción del índice y el grado de desarrollo. Las microrregiones se asemejan, tanto en aspectos culturales, productivos, económicos y de la colonización, como en fila, según el grado de desarrollo regional calculado. Se concluye que hay todavía mucho por hacer para lograr un desarrollo regional equitativo, mientras que los municipios de cada microrregion de la mesorregión. Palabras clave: desarrollo regional; análisis factorial; microrregion.

\footnotetext{
* Universidade Federal da Fronteira Sul, Chapecó, Santa Catarina, Brasil

** Universidade Estadual do Oeste do Paraná, Francisco Beltrão, Paraná, Brasil.
} 


\section{INTRODUÇÃO}

O tema desenvolvimento regional, nos últimos anos, tem conquistado espaço nas discussões, principalmente no ensino e nas pesquisas. Uma das razões disso concentra-se na necessidade de elaborar planos que atendam a diversidade e as realidades regionais, visto que as diversas regiões apresentam diferentes níveis de desenvolvimento, desencadeando diferenças significativas.

Identificar aspectos do desenvolvimento regional poderá auxiliar no desenvolvimento de políticas públicas de atendimento à população, podendo se configurar como apoio ao desenvolvimento. Além disso, outras regiões com características semelhantes podem entender melhor seu dinamismo, para também constituírem estratégias que possam ser base para o desenvolvimento regional. Como obstáculos, podem ser elencados alguns aspectos, dentre eles a insuficiência de serviços públicos, defasagem de infraestrutura logística, bem como de regulamentação bancária (HIRSCHMAN, 1958).

Nesse sentido, a atenção volta-se para construir um desenvolvimento mais focado nas especificidades de cada região, de forma a integrar os aspectos econômicos, sociais, ambientais, políticos e educacionais, entre outros. Para tanto, é de suma importância conhecer os aspectos que compõem cada espaço, bem como sua dinâmica interna.

Assim, este estudo tem como objetivo classificar os municípios das cinco microrregiões que formam a mesorregião oeste catarinense segundo o grau de desenvolvimento regional, utilizando a análise fatorial. Para tanto, está dividido em cinco partes, sendo a primeira a presente introdução. A segunda parte evidencia as principais referências nas quais o trabalho está fundamentado, e a terceira refere-se à metodologia utilizada. A quarta aborda os resultados e discussão sobre estes, e a quinta evidencia as considerações finais.

\section{DESENVOLVIMENTO REGIONAL MULTIDIMENSIONAL}

O desenvolvimento pode ser definido com base no contínuo aumento dos níveis de vida ${ }^{1}$, incluindo maior consumo de produtos e serviços básicos para o conjunto da população (SOUZA, 2005). Para Bresser-Pereira (2008), o desenvolvimento econômico de determinada região é um processo de acúmulo de capital que, aliado ao progresso técnico, possibilita aumento da produtividade, dos salários e do padrão médio de vida da população.

Lopes (2001) argumenta, no que tange ao desenvolvimento regional, que, devido às diversidades espaciais, é preciso formular políticas e planos capazes de serem concretizados, considerando as características de cada região. Entende-se que para tanto há necessidade de medir o desenvolvimento em cada região.

Mas, será possível quantificar o desenvolvimento de uma região? Vários autores elaboraram estudos com metodologias, iguais ou próximos, que buscaram medir o desenvolvimento, sendo que vários utilizaram, para esse fim, a Análise Fatorial (KAGEYAMA, 2004; ARRUDA, 2010; PAZ, 2012; CANODÁ, 2013).

Mensurar o desenvolvimento não é uma tarefa simples, pois envolve o levantamento de uma série de indicadores demográficos, sociais, econômicos, ambientais e institucionais que possam auxiliar no estudo do fenômeno (MELO; PARRÉ, 2007; MELO; SILVA, 2014). Na busca por quantificar o desenvolvimento, exige-se apurado senso crítico na escolha das técnicas e métodos de análise. Entende-se que a validade de um índice de desenvolvimento dependerá da qualidade dos dados utilizados que necessitam

\footnotetext{
${ }^{1} \mathrm{O}$ aumento dos níveis de vida acontece através de melhorias sociais e econômicas, como mais alimentação, melhor atendimento médico e odontológico, educação mais qualificada, mais segurança e melhor qualidade do meio ambiente (SOUZA, 2005).
} 
ser oficiais (CONTERATO; SCHNEIDER; WALQUI, 2007).

Por se tratar de uma formação multidimensional, o desenvolvimento regional perpassa diversos fatores econômicos, sociais, estruturais, educacionais e ambientais, entre outros, que podem influenciar a formação de determinada região. É provável que alguns, ou todos esses fatores, contribuíram para a formação da mesorregião Oeste Catarinense, localizada no Estado de Santa Catarina, englobando as microrregiões de São Miguel do Oeste, Chapecó, Xanxerê, Concórdia e Joaçaba.

\section{A MESORREGIÃO OESTE CATARINENSE}

A região denominada mesorregião Oeste Catarinense, formada a partir da divisão dos dois municípios criados, em
1917, pela Lei Estadual no 1.147, de 25 de agosto de 1917, no Estado Catarinense, a ser então colonizada, por muito tempo foi fruto de disputa entre Santa Catarina e o Paraná, bem como entre o Brasil e a Argentina. No início chegaram colonizadores europeus que iniciaram algumas atividades agrícolas e extrativistas. Hoje é uma das regiões mais importantes do Brasil no setor agroindustrial produtor de alimento (AREND; ORLOWSKI, 2012) e destaca-se no âmbito estadual na produção de grão e na criação de gado leiteiro.

Das seis mesorregiões que formam o Estado de Santa Catarina, a Oeste Catarinense, com 118 municípios, é a maior em tamanho e quantidade de municípios, sendo assim distribuídos: São Miguel do Oeste com 21 municípios, Chapecó com 38, Xanxerê com 17, Concórdia com 15 e Joaçaba com 27.

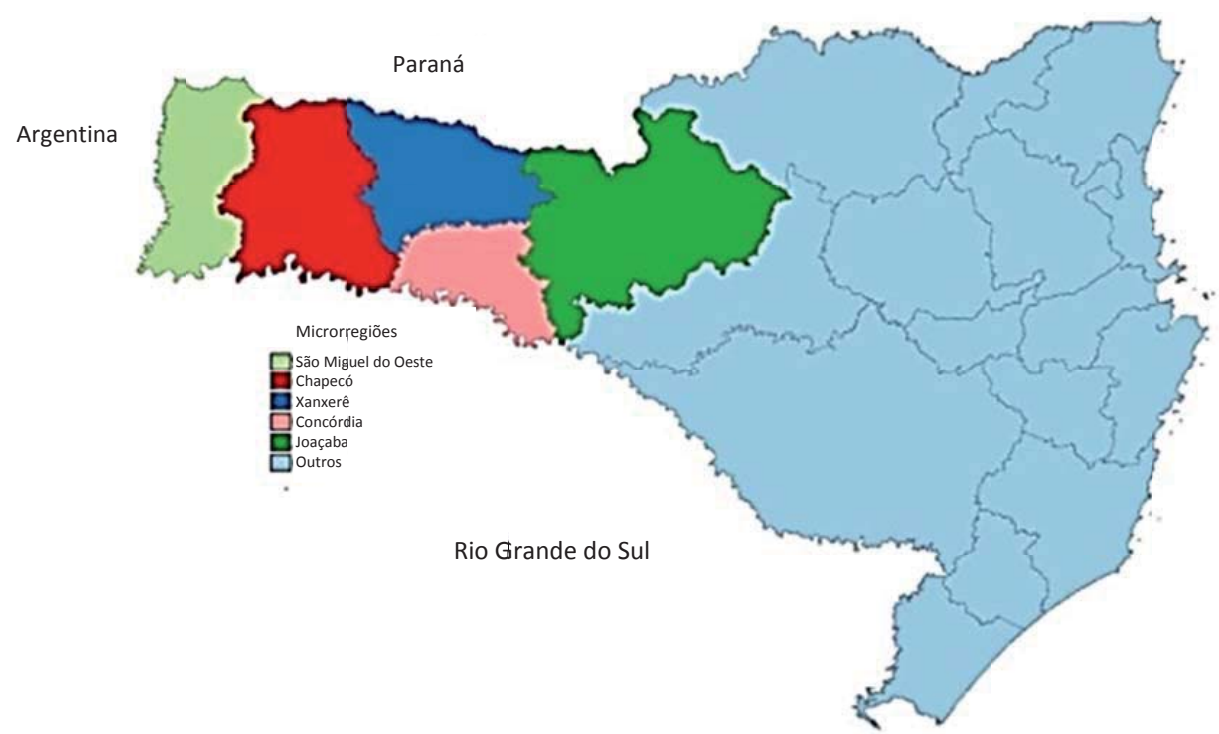

Figura 1 - A mesorregião Oeste Catarinense e as suas cinco microrregiões

Fonte: Elaboração própria, 2015.

O desenvolvimento dessa mesorregião baseia-se sobre a história de três grupos principais, que são os índios, os caboclos e os colonizadores europeus. A região apresentou processo lento e tardio de ocupação e integração ao modelo capitalista de produção. Foi com a chegada de descen- dentes europeus que houve melhoramento nas técnicas de utilização do solo e cultivo (RAMMÉ, 2011), sendo que, ao longo do tempo, a erva-mate, a agropecuária, a extração de madeira e a agroindústria passaram a ser as principais atividades econômicas desenvolvidas (MATTEI, 2010). 
Os colonizadores, quando se instalaram, desenvolveram técnicas de trabalho agrícola, com base familiar, capaz de atender as necessidades de sustento. Com o tempo teve início a construção de usinas hidrelétricas de diferentes tamanhos, fazendo uso, principalmente, dos recursos do rio Uruguai. Na década de 40, as atividades agrícolas, como a produção de milho, arroz e feijão, conquistaram maior espaço e, na segunda metade do século XX, o modelo agroindustrial, principalmente com a criação de suínos e aves, tornou essa mesorregião um polo agroindustrial do Estado (RAMMÉ, 2011) bem como do país.

O contínuo melhoramento genético da suinocultura e das aves bem como o aumento da escala de produção tornou-se uma das bases do desenvolvimento da mesorregião (THEIS; NODARI, 2000), junto com a produção leiteira. O sistema de integração entre pequenos agricultores e agroindústria veio a apresentar relevante importância. Além disso, a maior parte dos municípios, também, mantém sua base econômica nas atividades rurais, tendo destaque, segundo Mattei (2010) a produção de milho, feijão, arroz, fumo, soja, maçã e Laranja.

De acordo com Mattei (2010), o setor secundário apresenta relativo dinamismo com a indústria alimentar, de processamento de soja e com a indústria madeireira, principalmente na região de Caçador e Matos Costa. Por sua vez, o setor terciário tem menor destaque econômico, no qual o comércio apresenta alguma eficiência, principalmente nas cidades de Chapecó, Joaçaba, Videira, Concórdia e Caçador e o turismo, que fica restrito a algumas cidades que possuem águas termais (MATTEI, 2015) ou festas típicas. Cada microrregião apresenta alguns aspectos comuns e outros peculiares.

\section{METODOLOGIA}

Este estudo iniciou-se com base nos dados de cada município, passando pela análise de cada microrregião, possibilitando assim, uma visão da mesorregião Oeste Catarinense, quanto ao desenvolvimento regional.

Por questões de ordem estruturante, o referencial metodológico está concentrado no método utilizado para elaboração do Índice de Desenvolvimento Regional (IDRG) e do Grau de Desenvolvimento Regional (GDRG), bem como na descrição das variáveis utilizadas.

\section{1 Índice e grau de desenvolvimento regional}

Por meio da utilização de uma técnica de análise multivariada, chamada análise fatorial, levando em conta o caráter multidimensional de desenvolvimento que foi possível calcular o IDRG bem como o GDRG. Vários autores utilizaram a Análise Fatorial em seus estudos, cita-se Melo e Parré (2007), Bakke, Leite e Silva (2008), Arruda (2010), Paz (2012) Melo e Silva (2014).

Nos últimos tempos, o uso da análise fatorial aumentou em quase todas as áreas de pesquisa, principalmente aquelas relacionadas à economia e ao desenvolvimento. O propósito dessa técnica multivariada é definir a composição própria que se forma entre as variáveis que fazem parte de determinado estudo. Segundo Hair et al (2009), por meio da análise fatorial, pode-se chegar a estruturas de inter-relações/correlações que se formam por meio das variáveis analisadas. Com isso é possível extrair os fatores que representam as dimensões.

Quando o objeto de estudo é uma ou mais regiões, os fatores extraídos auxiliam a identificar o estágio de desenvolvimento (MELO; PARRÉ, 2007) e ainda possibilitam ao pesquisador criar indicadores, o que não seria possível somente por meio 
das variáveis iniciais (FÁVERO et al., 2009).

O modelo de análise fatorial pode ser expresso por meio de uma combinação linear entre as variáveis e os fatores (FÁVERO et al., 2009):

$X_{i}=A_{i 1} F_{1}+A_{i 2} F_{2}+\ldots+A_{i k} F_{k}+U_{i}+E_{i}$

Onde: $X_{i}$ - variáveis $i$ analisadas; $A_{i k}$ - cargas fatoriais; $F_{k}$ - fatores comuns; $U_{i}$ - fator único; $E_{i}$ - fator de erro.

Dentre os vários métodos possíveis de serem utilizados para extração dos fatores, optou-se por utilizar o dos componentes principais, contribuindo, dessa forma, para a variância comum $h_{i}^{2}$ (comunalidade ${ }^{2}$ ) (HAIR et al., 2009). Tendo decidido o método do modelo, passou-se à extração dos fatores. Nesse caso, optou-se pela técnica da raiz latente ou dos autovalores, que consideram significantes somente aqueles maiores que 1. Passou-se então à rotação dos fatores.

Com a rotação, a variância é redistribuída dos primeiros fatores para os últimos, visando chegar a um padrão fatorial mais simples e mais significativo (HAIR et al., 2009). Neste estudo, foi utilizada a técnica de rotação ortogonal varimax, possibilitando a interpretação das cargas fatoriais.

Com esses passos, percebeu-se que os cálculos atenderam os preceitos exigidos pela análise fatorial. No passo seguinte, foram utilizados os scores fatoriais para organização do IDRG e do GDRG.
Os escores fatoriais possuem distribuição normal, isto é, têm média zero e variância um, podendo ser utilizados para indicar uma posição relativa de cada observação (município). Assim, foi possível construir o índice Bruto de Desenvolvimento (IBD), com base na matriz de escores fatoriais, capaz de hierarquizar as observações.

Esse índice é proposto por Melo (2006) através do cálculo da média ponderada dos fatores pertencentes a cada observação. Com o valor de cada fator, pondera-se cada um deles pela sua variância, expresso na equação:

$$
I B D_{i}=\frac{\sum_{i=1}^{N}\left(W_{i} f_{i}\right)}{\sum_{i=1}^{N} W_{i}}
$$

Em que IDB é o Índice Bruto de Desenvolvimento, $N$ é o número de fatores, $W_{i}$ é a proporção da variância explicada individualmente por fator e $f_{i}$ é o escore fatorial.

A partir do IBD, por interpolação linear, em que o menor e o maior valor do IDB foram considerados como 0 e 100 , calculou-se o IDRG correspondente a cada observação (município). Procedeu-se então o cálculo da média e o desvio padrão em torno da média para classificar os municípios quando ao GDRG, conforme Quadro 1.

\footnotetext{
${ }^{2}$ É quanto determinada variável compartilha de seus valores, com todas as outras variáveis do estudo. É também o quanto da variância comum é explicada pelos fatores comuns.
} 


\begin{tabular}{|l|l|l|}
\hline \multicolumn{1}{|c|}{ Grau de desenvolvimento (GDRG) } & \multicolumn{1}{c|}{ Limite inferior } & \multicolumn{1}{c|}{ Limite Superior } \\
\hline Extremamente Alto (EA) & Média $+4 \sigma+0,01$ & até 100 \\
\hline Muito Alto (MA) & média $+3 \sigma+0,01$ & média $+4 \sigma$ \\
\hline Alto $(\mathrm{A})$ & média $+2 \sigma+0,01$ & média $+3 \sigma$ \\
\hline Médio Alto (MDA) & média $+1 \sigma+0,01$ & média $+2 \sigma$ \\
\hline Médio (M) & Média & média $+1 \sigma$ \\
\hline Médio Baixo (MDB) & média $-1 \sigma$ & média $-0,01$ \\
\hline Baixo (B) & média $-2 \sigma$ & média $-1 \sigma-0,01$ \\
\hline Muito Baixo (MB) & média $-3 \sigma$ & média $-2 \sigma-0,01$ \\
\hline Extremamente Baixo (EB) & até 0,00 & média $-3 \sigma-0,01$ \\
\hline
\end{tabular}

Quadro 1 - Formação do GDR

Fonte: Organização própria

Para verificar a adequabilidade do modelo, utilizou-se a medida de adequação chamada Kaiser-Meyer-Olkin (KMO), que é a soma dos quadrados das correlações de todas as variáveis, dividida por essa mesma soma, acrescentada da soma dos quadrados das correlações parciais de todas as variáveis. O KMO compara a magnitude dos coeficientes de correlação observados com as magnitudes dos coeficientes de correlação parcial, que varia de 0 a 1. Quanto mais próximo de um, tanto melhor.

Foi ainda realizado o teste Barlett Test of Sphericity (BTS). Este, testa a hipótese de que a matriz de correlação é uma matriz identidade e, nesse caso, não poderia continuar o estudo, pois não haveria correlação entre as variáveis. Destaca-se também que, nesta pesquisa, utilizou-se o software Statistical Package for the Social Sciences (SPSS) (versão 18) para realizar os cálculos estatísticos.

\subsection{Organização das variáveis e fonte de pesquisa}

O estudo do desenvolvimento, por tratar-se de um fenômeno multidimensional, ultrapassa as questões econômicas, envolvendo um conjunto de indicadores que estão ligados entre si. No caso deste estudo, as variáveis estão ligadas a aspectos de bem-estar social e equidade, educação, estrutura e desempenho econômico, população e migração, meio ambiente e sustentabilidade, conforme quadro 1 . As variáveis que compõem essas dimensões foram escolhidas por sua relação com a definição multidimensional de desenvolvimento.

No que tange ao número de variáveis, não há um quantitativo exato a ser utilizado no modelo fatorial. Quanto às amostras, dificilmente será possível realizar a análise fatorial com menos de 50 observações e, preferencialmente, deve ser igual ou maior de 100 (HAIR et al, 2009). O autor sugere ainda que haja, no mínimo, 5 observações para cada variável. No caso desta pesquisa, são 17 variáveis e 118 observações, atendendo, dessa forma, a orientação estabelecida. 


\begin{tabular}{|c|c|}
\hline Variável & Nome \\
\hline $\mathrm{x} 1$ & Esperança de vida ao nascer \\
\hline $\mathrm{x} 2$ & Mortalidade infantil (até 1 ano de idade) \\
\hline$x 3$ & Expectativa de anos de estudo aos 18 anos de idade \\
\hline$x 4$ & $\begin{array}{l}\text { \% da população com } 6 \text { a } 17 \text { anos na escola (taxa de atendimento escolar da } \\
\text { população de } 6 \text { a } 17 \text { anos de idade) }\end{array}$ \\
\hline$x 5$ & $\begin{array}{l}\% \text { da população ocupada, que possui ensino fundamental completo (18 anos } \\
\text { ou mais) }\end{array}$ \\
\hline$x 6$ & Renda per capita \\
\hline$x 7$ & \% dos ocupados no setor agropecuário (18 anos ou mais) \\
\hline$x 8$ & $\%$ dos ocupados no setor extrativo mineral (18 anos ou mais) \\
\hline$x 9$ & \% dos ocupados no setor comércio (18 anos ou mais) \\
\hline $\mathrm{x} 10$ & \% de ocupados no setor serviços (18 anos ou mais) \\
\hline $\mathrm{x} 11$ & \% da população em domicílio com coleta de lixo \\
\hline $\mathrm{x} 12$ & IDHM \\
\hline x13 & $\begin{array}{l}\text { \% da população com } 5 \text { a } 6 \text { anos na escola (percentual da população com } 5 \text { a } 6 \\
\text { anos de idade que frequentam a escola) }\end{array}$ \\
\hline $\mathrm{x} 14$ & Taxa de fecundidade total \\
\hline $\mathrm{x} 15$ & $\%$ de pobres \\
\hline $\mathrm{x} 16$ & Índice de Gini \\
\hline x17 & Índice de Theil - L \\
\hline
\end{tabular}

Quadro 2 - Variáveis que compõe o estudo e a dimensão a qual está ligada

Fonte: Organização própria, 2015

\section{RESULTADOS E DISCUSSÕES}

O índice de desenvolvimento Regional foi calculado com base em dados do ano 2010 e tendo, como unidade de análise, 118 municípios do Estado de Santa Catarina, que compõe a Mesorregião Oeste Catarinense.

Após a rotação ortogonal, utilizando a técnica varimax, utilizando os dados das variáveis, indicadas no quadro 2 , foi possível extrair cinco fatores com raiz característica maior que um, por meio do método dos componentes principais. A contribuição desses fatores para explicar a variância total dos indicadores é significativa, uma vez que a variância total acumulada chegou a $81,800 \%$, conforme tabela 1 .

Tabela 1 - Raiz característica, percentual explicado individualmente por fator e variância acumulada

\begin{tabular}{cccc}
\hline Fator & Raiz Característica & Variância explicada pelo fator (\%) & Variância Acumulada (\%) \\
\hline F1 & 3,846 & 22,625 & 22,625 \\
F2 & 3,755 & 22,089 & 44,714 \\
F3 & 2,459 & 14,464 & 59,177 \\
F4 & 2,274 & 13,377 & 72,554 \\
F5 & 1,572 & 9,246 & 81,800 \\
\hline
\end{tabular}

Fonte: Resultado da pesquisa, 2015

O teste BST apresentou valor de 2550,711 mostrando-se, dessa forma, significativo a $0,05 \%$, sendo assim, rejeitada a hipótese nula de que a matriz de correlação é uma matriz identidade.
A estatística KMO apresentou valor de 0,730 indicando que a utilização da análise fatorial é adequada.

Também foram extraídas as cargas fatoriais, apresentadas na tabela 2 , bem 
como a comunalidade para cada variável. Foram consideradas para o estudo, as comunalidades e cargas fatoriais superiores a 0,550, conforme Hair et al. (2009). As cargas fatoriais menores que 0,550 foram excluídas das tabelas.

Tabela 2 - Cargas Fatoriais e Comunalidades calculadas.

\begin{tabular}{|c|c|c|c|c|c|c|}
\hline \multirow{2}{*}{ Indicadores } & \multicolumn{5}{|c|}{ Cargas Fatoriais } & \multirow{2}{*}{ Comunalidades } \\
\hline & $F_{1}$ & $F_{2}$ & $F_{3}$ & $\overline{F_{4}}$ & $\overline{F_{5}}$ & \\
\hline$X_{1}$ & 0,952 & & & & & 0,933 \\
\hline$X_{2}$ & $-0,953$ & & & & & 0,933 \\
\hline$X_{6}$ & 0,704 & & & & & 0,839 \\
\hline$X_{12}$ & 0,730 & & & & & 0,951 \\
\hline$X_{14}$ & $-0,572$ & & & & & 0,668 \\
\hline $\boldsymbol{X}_{15}$ & $-0,603$ & & & & & 0,819 \\
\hline$X_{5}$ & & 0,884 & & & & 0,888 \\
\hline$X_{7}$ & & $-0,921$ & & & & 0,923 \\
\hline$X_{9}$ & & 0,865 & & & & 0,781 \\
\hline $\boldsymbol{X}_{10}$ & & 0,890 & & & & 0,823 \\
\hline$X_{3}$ & & & 0,802 & & & 0,686 \\
\hline$X_{4}$ & & & 0,801 & & & 0,701 \\
\hline$X_{13}^{4}$ & & & 0,668 & & & 0,573 \\
\hline$X_{16}^{10}$ & & & & 0,963 & & 0,975 \\
\hline$X_{17}$ & & & & 0,974 & & 0,982 \\
\hline$X_{8}$ & & & & & $-0,792$ & 0,660 \\
\hline$X_{11}^{\circ}$ & & & & & 0,852 & 0,768 \\
\hline
\end{tabular}

Fonte: Resultados da pesquisa, 2015.

O fator 1 está relacionado positivamente com as variáveis $X_{1}, X_{2}, X_{6}, X_{12}, X_{14}, X_{15}$, relacionadas com a expectativa de vida das pessoas, renda per capita, índice de desenvolvimento humano municipal, denotando aspectos importantes como população e migração, estrutura e desempenho econômico e bem-estar social e equidade.

O fator 2 está forte e positivamente ligado as variáveis $X_{5}, X_{7}, X_{9}, X_{10}$ que versam basicamente sobre população ocupada, relacionando-se a estrutura e desempenho econômico dos municípios, relativamente à força de trabalho. Esse fator participa com 22,089\% da variância explicada pelo fator.

O fator 3 é composto por três variáveis, sendo que se encontra positivamente relacionado com todas elas. As variáveis são $X_{3}, X_{4}, X_{13}$ que acumulam questões referentes à educação, como expectativa de anos de estudo e frequência escolar. Esse fator participa da variância explicada pelo fator com $14,464 \%$ e reúne somente variáveis ligadas a questões educacionais.

O fator 4 está ligado, positivamente, às variáveis $X_{16}, X_{17}$ relacionadas a questões de bem-estar social e equidade, apontando a possíveis concentrações e distribuições de renda. Ele ainda explica 13,377\% da variância do modelo.

Por fim o fator 5, que está positivamente ligado às dimensões $X_{11}, X_{8}$ , relativas a itens relacionados ao meio ambiente e sustentabilidade, bem como de estrutura e desempenho econômico. Esse fator explica 9,246\% da variância.

Realizada esta análise, pode-se voltar a atenção para a elaboração do índice de desenvolvimento regional (IDRG) para cada município. Primeiramente calculou-se o Índice de Desenvolvimento Bruto (IDB), a partir dos escores fatoriais de cada 
variável e da variância explicada de cada fator (MELO; PARRÉ, 2007). Nesse caso, os escores foram normalizados, passando a ter média zero e desvio padrão 1 . $\mathrm{O}$ próximo passo foi calcular o IDRG, por interpolação, a partir do IDB. Também foi calculado o IDRG médio - 45,05 - e o desvio padrão - 12,98 - em torno da média. Por fim foram organizadas as categorias de classificação para calcular o grau de desenvolvimento regional (GDRG), conforme quadro 3.

\begin{tabular}{|l|c|c|}
\hline \multicolumn{1}{|c|}{ Classificação } & Limite inferior & Limite superior \\
\hline Extremamente Alto (EA) & 97,03 & 100,00 \\
\hline Muito Alto (MA) & 84,04 & 97,02 \\
\hline Alto (A) & 71,04 & 84,03 \\
\hline Médio Alto (MDA) & 58,05 & 71,03 \\
\hline Médio (M) & 45,05 & 58,04 \\
\hline Médio Baixo (MDB) & 32,05 & 45,04 \\
\hline Baixo (B) & 19,06 & 32,04 \\
\hline Muito Baixo (MB) & 6,06 & 19,05 \\
\hline Extremamente Baixo (EB) & 0,00 & 6,05 \\
\hline
\end{tabular}

Quadro 3 - Categoria de classificação segundo grau de desenvolvimento rural, e intervalos/limites

Fonte: Elaboração própria, 2015.

Com base nesses dados, organizou-se a figura 2, que apresenta os municípios, da mesorregião Oeste Catarinense, conforme o GDRG, calculado. É possível perceber que apenas um município apresentou GDRG extremamente alto. A mesma situação para GDRG muito alto, em que também somente um município ficou classificado. Classificados como Alto, ficaram 8 municípios, e médio alto,
16. Outros 32 foram classificados com GDRG médio e, como médio, foram 39 municípios. O grau de desenvolvimento baixo apresentou 14 municípios e, muito baixo, 6. Por fim 3 municípios ficaram classificados com grau de desenvolvimento regional extremamente baixo. Há condições de perceber algumas aglomerações geográficas, conforme o grau de desenvolvimento.

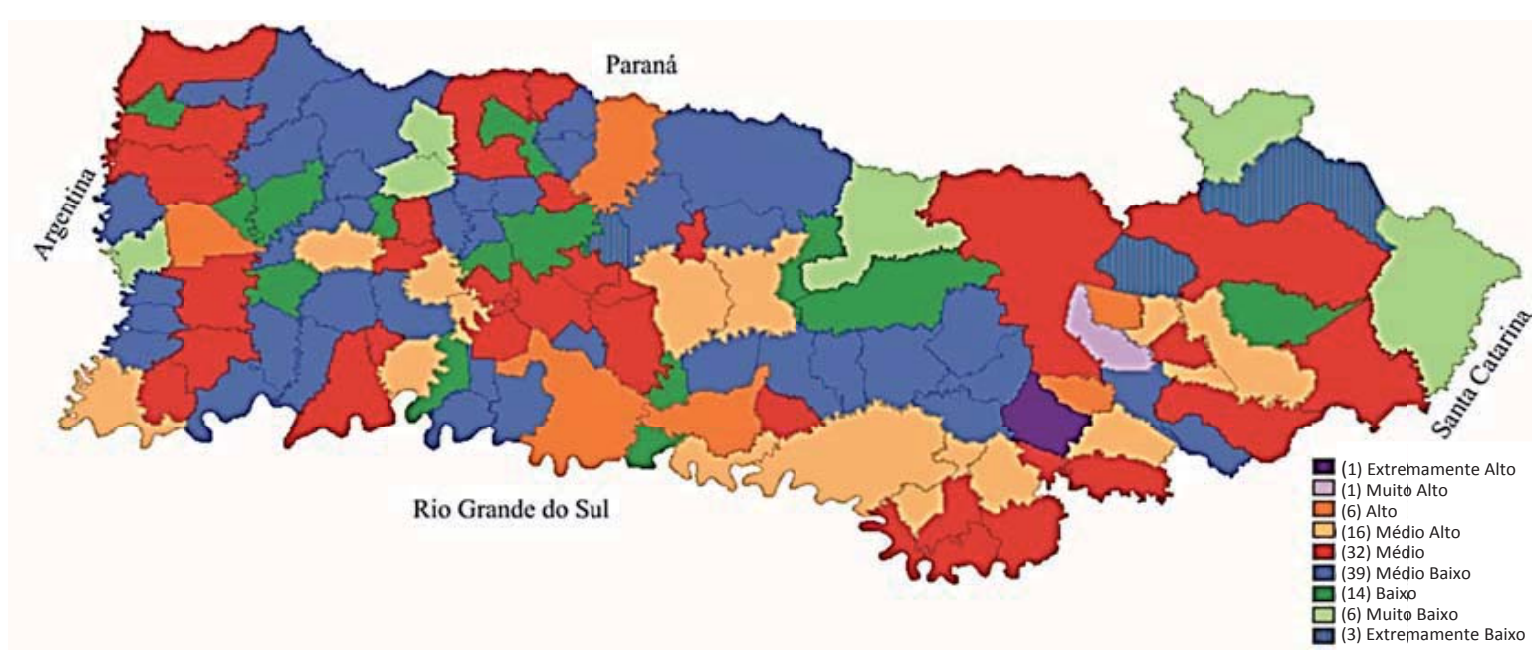

Figura 2 - Distribuição espacial do grau de desenvolvimento regional dos municípios da Mesorregião Oeste Catarinense Fonte: Resultados da pesquisa, 2015. 
Por microrregiões, a tabela 3 apresenta o número de municípios conforme seu GRRG.

Tabela 3 - Número de municípios por mesorregião, segundo grau de desenvolvimento rural

\begin{tabular}{c|ccccc}
\hline \multirow{2}{*}{ GDRG } & \multicolumn{5}{c}{ MICRORREGIÕES } \\
\cline { 2 - 6 } & São Miguel do Oeste & Chapecó & Xanxerê & Concórdia & Joaçaba \\
\hline EA & 00 & 00 & 00 & 00 & 01 \\
MA & 00 & 00 & 00 & 00 & 01 \\
A & 01 & 01 & 01 & 01 & 02 \\
MDA & 01 & 04 & 02 & 04 & 05 \\
M & 06 & 09 & 05 & 04 & 08 \\
MDB & 09 & 16 & 05 & 04 & 05 \\
B & 03 & 06 & 02 & 02 & 01 \\
MB & 01 & 02 & 01 & 00 & 02 \\
EB & 00 & 00 & 01 & 00 & 02 \\
\hline Total & 21 & 38 & 17 & 15 & 27 \\
\hline
\end{tabular}

Fonte: Resultados da pesquisa, 2015.

De modo geral, são poucos os estudos envolvendo a região geográfica formada pelas cinco microrregiões apresentadas na tabela 3, que aglutinam aspectos ligados à população, migração, educação, economia, bem-estar social e meio ambiente. Estudos envolvendo essas abordagens são cada vez mais importantes e necessários para conhecer a região e possibilitar a criação de políticas que contribuam para o desenvolvimento regional.

A microrregião São Miguel do Oeste é formada por 21 municípios, o que corresponde a $17,80 \%$ do total de municípios da mesorregião. O município que se destacou, apresentando maior GDRG, classificado como alto, foi São Miguel do Oeste. De outro lado, o município que presentou o menor GDRG, classificado como muito baixo, foi Bandeirantes.

A colonização dessa microrregião aconteceu, principalmente por imigrantes italianos e alemães, mas também, em minoria, participaram os russos, na cidade de Riqueza, e os poloneses, em Belmonte e Descanso. Há destaque para as atividades econômicas ligadas à agropecuária e que são incrementadas pela indústria e pelos serviços, enquanto, na agricultura, tem maior importância a produção de milho, feijão, trigo, fumo e soja; na pecuária, é o gado de corte e de leite que se sobressai (MARQUES, 2007).

A população da microrregião, tendo o ano de 2000 e 2010 como referências, apresentou pequeno crescimento. No primeiro ano, a população total era de 171.160 habitantes passando a 174.732 em 2010. Enquanto esse mesmo cenário se repetiu na área urbana, que passou de 81.664 habitantes para 101.195, ocorreu o inverso na área rural, onde a população reduziu de 89.496 para 73.537 habitantes (IBGE, 2015).

Esse deslocamento populacional das áreas rurais para as áreas urbanas pode ser explicado pela implantação das agroindústrias de carnes e pelo desenvolvimento do comércio, bem como pela criação de faculdades que atraem, principalmente, os jovens. Nesse sentido, um dos grandes desafios dos governantes continua sendo a criação de políticas públicas que possam atender a população.

A microrregião de Chapecó, contendo 38 municípios, representa 32,20\% do total da mesorregião. A distribuição segundo o GDRG assemelhou-se à 
apresentada pela microrregião de São Miguel do Oeste. O município que se destacou, com o maior grau, dentro da microrregião, foi Chapecó, sendo alto. Dois municípios apresentaram grau de desenvolvimento muito baixo, sendo São Bernardino e Saltinho. Como o primeiro ficou com índice de desenvolvimento de 17,57 , e o segundo, de 17,05, aponta-se Saltinho como sendo o que apresentou menor GDRG.

Destacam-se, nessa região, os frigoríficos, que começaram a ser instalados na década de 1940, e as cooperativas na década de 1960. As principais atividades econômicas que são desenvolvidas nessa microrregião estão ligadas à agropecuária. As propriedades rurais, na sua maior parte, estão ligadas à agricultura familiar, na qual $96,61 \%$ possuem até 50 ha (THEIS; NODARI, 2000), sendo o milho, a soja, o fumo e trigo as principais culturas agrícolas, e a criação de suínos, aves e gado leiteiro, as principais atividades da pecuária. Essa região, também vem se destacando na geração de empregos formais (THEIS; NODARI, 2000).

No que tange à saúde, indica-se que, nessa região, os investimentos realizados nas unidades de saúde, desencadeiam os melhores resultados possíveis no atendimento à população (KAVESKI; MAZZIONI; HEIN, 2013) entendendo, assim, como eficiente o atendimento do SUS. Entretanto não é a realidade de todos os municípios, pois alguns ainda precisam melhorar, como é o exemplo de Caibi, segundo o estudo de Kaveski, Mazzioni e Hein (2013).

Na microrregião de Xanxerê, o município que se destacou na classificação foi São Domingos apresentando GDRG alto. Já o município que ficou com menor grau foi Entre Rios, sendo classificado como extremamente baixo. A população total, na microrregião de Xanxerê, em 10 anos, cresceu cerca de $7,18 \%$, passando de 142.257 habitantes, em 2000, para 152.465, em 2010. Esse aumento foi acompanhado pela população urbana, que passou de 85.859 para 104.253 habitantes. Assim como nas outras microrregiões, a população rural diminuiu, pois, no ano 2000, era formada por 56.398 habitantes e, em 2010, passou a ter 48.212 (IBGE, 2015).

Essa microrregião compõe-se por pequenas propriedades rurais que têm como uma das principais atividades econômicas o gado leiteiro, sendo responsável por grande parte da produção estadual (DESCHER et al., 2009). Também é a segunda maior produtora de grãos do estado de Santa Catarina, sendo o milho e a soja as principais culturas. $\mathrm{O}$ déficit encontra-se principalmente na capacidade de armazenagem dos grãos produzidos.

Segundo estudo de Kaveski, Mazzioni e Hein (2013), essa microrregião tem eficiência quanto ao emprego dos recursos destinados à saúde pública e, dentro da mesorregião Oeste Catarinense, é a que apresenta melhores resultados.

$\mathrm{Na}$ microrregião de Concórdia, o município com maior grau de desenvolvimento foi Seara, que ficou classificado como alto. De outro lado, os municípios de Paial e Arvoredo ficaram classificados como baixo. Enquanto Paial apresentou índice de 30,93, Arvoredo obteve 29,28, sendo este, classificado na última posição, dentro da microrregião.

A população total da microrregião de Concórdia apresentou, entre 2000 e 2010 , crescimento de $2,93 \%$. Nesse mesmo período, enquanto a população urbana aumentou $20,25 \%$, a população rural reduziu 19,39\% (IBGE, 2015). Essa microrregião destaca-se na competitividade agroindustrial, com produção familiar, tendo em vista que, no município de Concórdia, está localizada a BrFoods (até pouco tempo atrás, Sadia) e, no município de Seara, a Seara Alimentos.

Essas questões fizeram dessa região um modelo de desenvolvimento agrário brasileiro, principalmente pela distribuição de renda entre os produtores (ALVES, 2008). Outras importantes atividades 
estão ligadas à criação de gado de leite e de corte, bem como à produção de grãos, destacando-se o milho. No caso da agroindústria, destacam-se a criação de suínos e aves.

Na educação, essa microrregião, apresentava, no ano de 1991, 6,03\% de analfabetismo em pessoas de 7 a 14 anos. Já no ano de 2000, esse percentual caiu para $2,07 \%$. A evasão escolar também apresentou redução, pois enquanto era de $13,48 \%$ no ano de 1991 passou a ser de 2,06 no ano 2000. E a educação pode ser considerada de elevada importância para o desenvolvimento regional, uma vez que, melhorando o nível educacional, obtém-se capacidade de produzir força de trabalho mais qualificada, que poderá ter rendimentos mais elevados do que aqueles que não possuem ensino (BLUESTONE, 1993).

A microrregião de Joaçaba foi a única que apresentou municípios distribuídos em todas as faixas de classificação. Os municípios com GDRG extremamente alto e muito alto, foram Joaçaba e Treze Tílias, respectivamente. Por outro lado, apresentou mais municípios classificados como extremamente baixo, do que as outras microrregiões, sendo Macieira com índice 5,66, e Calmon com índice 0,00.

O processo de colonização dessa microrregião ocorreu, principalmente, entre as décadas de 1910 e 1960, sendo a maioria dos colonizadores descendentes de italianos que haviam se instalado em terras gaúchas, em especial nas cidades de Bento Gonçalves e Caxias do Sul. Atualmente, é maior o número de pessoas que saem dessa microrregião do que aquelas que entram fixando moradia (HENRIQUES; MATTEI, 2013).

A economia está baseada na produção agropecuária, responsável por certa de $12 \%$ dos empregos, e na agroindústria. Há destaque para a produção de maçã, no município de Fraiburgo, e de uva/vinho, no município de Videira. Já os municípios de Caçador e Matos Costa destacam-se na indústria de madeira.

\section{CONSIDERAÇÕES FINAIS}

Este estudo buscou analisar o desenvolvimento das microrregiões que formam a mesorregião do Oeste Catarinense, a fim de classificar os municípios segundo o grau de desenvolvimento regional. Para tanto, utilizou a análise fatorial com base em 17 variáveis multidimensionais. Destaca-se que o índice e o grau de desenvolvimento regional (GDRG), que foram calculados, refletem uma posição relativa e, não, a posição absoluta.

A partir dos indicadores das variáveis utilizadas, foi possível extrair cinco fatores que indicam as principais características envolvendo o desenvolvimento regional, bem como aspectos da realidade da mesorregião Oeste Catarinense.

Dos 118 municípios que formam a mesorregião, 56 deles, correspondendo a $47,46 \%$, apresentaram GDRG acima da média calculada. Os outros 53,54\% ficaram classificados abaixo da média. Percebe-se, quanto à classificação, uma homogeneidade em todas as microrregiões, uma vez que, em todas elas, a maioria dos municípios ficaram classificados como médio alto, médio, médio baixo e baixo.

De modo geral, percebe-se que a mesorregião Oeste Catarinense caracteriza-se pela diversidade, mas também por diferenças que se ampliam. Essa realidade revela que há necessidade de maior atenção na formulação de políticas, tendo em vista proporcionar desenvolvimento aquelas regiões menos favorecidas.

Conclui-se que existem certos aglomerados de municípios, conforme o grau de desenvolvimento. Também se conclui que os municípios contíguos àqueles classificados como extremamente alto ou muito alto, estão classificados, com GDRG, médio alto para cima, indicando que determinada região em desenvolvimento desencadeia efeitos propulsores, iniciando processo cumulativo, propagando o desenvolvimento nas proximi- 
dades, conforme indicam Myrdal (1965) e Hirschman (1958).

Enfatiza-se que, embora alguns municípios tenham sido classificados com grau de desenvolvimento médio alto, alto, muito alto e extremamente alto, há espaço e tempo para avançar em todos os aspectos e dimensões do desenvolvimento. Talvez algumas variáveis que não foram utilizadas neste estudo revelem outras dificuldades ou necessidades das regiões. Destaca-se ainda a possibilidade de continuar este estudo com outras técnicas, tais como análise de cluster, painel de sustentabilidade ou ainda regressão, perfazendo e aprofundando tanto aspectos destacados neste estudo, como outros que podem ser descobertos.

Os resultados desta pesquisa mostram que o modelo de análise proposto auxilia a identificar diferenças e necessidades nas diversas realidades de uma região. Os resultados, unidos com as análises, podem auxiliar na criação de possíveis políticas públicas, capazes de auxiliar a minimizar as diferenças regionais.

\section{REFERÊNCIAS}

ALVES, A. S. Paralelo do desenvolvimento socioeconômico das microrregiões de Rio do Sul, São Bento e Concórdia. 2008. 128f. Monografia (Graduação em Ciências Econômicas) - Centro Sócio Econômico, Universidade Federal de Santa Catarina, Florianópolis, SC, 2008.

AREND, S. C.; ORLOWSKI, R. F. O desenvolvimento regional da Amosc a partir das teorias da base exportadora e dos polos de crescimento. REDES, Santa Cruz do Sul, v. 17, n. 1, p. 141-163, jan./abr. 2012.

ARRUDA, C. S. Índice de desenvolvimento sustentável e agronegócio nos municípios do estado de Goiás: uma análise multivariada. 2010.126f. Dissertação (Mestrado em Agronegócio) Universidade Federal de Goiás, Goiânia, GO, 2010.

BAKKE, H. A.; LEITE, A. S. M.; SILVA, L. B. Estatística multivariada: uma aplicação da análise fatorial na engenharia da produção.
Revista Gestão Industrial, Ponta Grossa, v. 4, n. 4, p. 1-14, 2008.

BLUESTONE, B. UMASS/BOSTON: an economic impact analysis. Boston: University of Massachusetts, jan. 1993.

BRESSER-PEREIRA, L. C. Crescimento e desenvolvimento econômico. BRESSERPEREIRA Website, 2008. Disponível em: $<$ http:/ / www.bresserpereira.org.br>. Acesso em: 10 set. 2015.

CANODÁ, L. A. Índice de Desenvolvimento Rural Sustentável. 2013. 170f. Tese (Doutorado em Ciências) - Escola Superior de Agricultura "Luiz de Queiroz", Universidade de São Paulo, Piracicaba, SP. 2013.

CONTERATO, M. A.; SCHNEIDER, S.; WALQUI, P. D. Desenvolvimento rural no estado do Rio Grande do Sul: uma análise multidimensional de suas desigualdades regionais. Redes, Santa Cruz do Sul, v. 12, n. 2, maio/ago. 2007.

FÁVERO, L. P. et al. Análise de dados: modelagem multivariada para tomada de decisões. Rio de Janeiro: Elsevier, 2009.

HAIR, J. F. et al. Análise multivariada de dados. 6. ed. Porto Alegre: Bookman, 2009.

HENRIQUES, F. MATTEI, L. F. O processo migratório em Santa Catarina: evidências a partir da microrregião de Joaçaba. Geosul, Florianópolis, v. 28, n. 56, p. 65-88, jul./dez. 2013.

HIRSCHMAN, A. O. The strategy of economic development. New Haven: Yale University Press, 1958.

INSTITUTO BRASILEIRO DE GEOGRAFIA E ESTATÍSTICA (IBGE), 2015. Disponível em: <http://www.ibge.gov.br>. Acesso em: 2 jul. 2015.

KAGEYAMA, A. Desenvolvimento rural: conceito e medida. Cadernos de Ciência e Tecnologia, Brasília, v. 21, n. 3, set./ dez. 2004.

KAVESKI, I. S.; MAZZIONE, S.; HEIN, N. A eficiência na utilização de recursos no setor de saúde: uma análise dos municípios do Oeste Catarinense. In: ENCONTRO NACIONAL DOS CURSOS DE GRADUAÇÃO EM ADMINISTRAÇÃO (ENANGRAD), 24., 29 jul. - 2 out. 2013, Florianópolis. Anais... Florianópolis, SC, 2013. 
LOPES, A. S. Desenvolvimento regional problemática, teoria, modelos. 5. ed. Lisboa: Fundação Calouste Gulbenkiam, 2001.

MARQUES, A. F. Paralelo de desenvolvimento socioeconômico das microrregiões de Criciúma, Canoinhas e de São Miguel D'Oeste. 2007. 161f. Monografia (Graduação em Ciências Econômicas) - Departamento de Ciências Econômicas, Universidade Federal de Santa Catarina, Florianópolis, SC, 2007.

MATTEI, L. Economia catarinense: crescimento com desigualdades regionais. In: ENCONTRO DE ECONOMIA CATARINENSE, 4., 29 a 30 abr. 2010, Criciúma, SC. Anais... Criciúma: UNESC, 2010. Disponível em: <http:/ / www. apec.unesc.net>. Acesso em: 5 ago. 2015.

MELO, C. O. Caracterização do desenvolvimento rural dos municípios paranaenses: uma análise com base na estatística multivariada. 2006. 127 f. Dissertação (Mestrado em Economia) - Centro de Ciências Sociais Aplicadas, Universidade Estadual de Maringá. Maringá, PR, 2006.

MELO, C. O. PARRÉ, J. L. Índice de desenvolvimento rural dos municípios paranaenses: determinantes e hierarquização. Revista de Economia e Sociologia Rural, Rio de
Janeiro, v. 45, n. 2, p. 329-265, abr./jun. 2007.

MELO, C. O. SILVA, G. S. Desenvolvimento rural dos municípios da região sudoeste do Paranaense: uma proposta de medida através da Análise Fatorial. Organizações Rurais \& Agroindustriais, Lavras, v. 16, n. 1, p. 33-45, 2014.

MYRDAL, G. Teoria econômica e regiões subdesenvolvidas. Rio de Janeiro: Saga, 1965.

PAZ, D. Nível de desenvolvimento sócio econômico dos municípios paranaenses em 2010: análise fatorial. 2012. 100f. Dissertação (Mestrado em Economia Regional) - Centro de Estudos Sociais Aplicados, Universidade Estadual de Londrina, Londrina, PR, 2012.

RAMMÉ, J. Desenvolvimento municipal: análise populacional da Mesorregião do Oeste Catarinense. Revista Estudos do CEPE, Santa Cruz do Sul, n. 34, p. 242-262, jul./ dez. 2011.

SOUZA, N. J. Desenvolvimento econômico. 5. ed. São Paulo: Atlas, 2005.

THEIS, I. NODARI, T. S. A agroindústria de aves e o desenvolvimento regional do meio oeste de Santa Catarina. Cadernos de Economia, Chapecó, n. 7, p. 07-28, jul./dez. 2000.

\section{Sobre os autores:}

Sérgio Begnini: Mestre em Gestão e Desenvolvimento Regional, Universidade Federal da Fronteira Sul. E-mail: sergiobegnini@gmail.com

Lirane Elize Defante Ferreto de Almeida: Doutora em Saúde Coletiva, Universidade Estadual do Oeste do Paraná. E-mail: liraneferreto@uol.com.br 